August 1986

\title{
Dynamic Considerations in Psychiatric Crisis Intervention
}

\author{
Keith Cheng, MD \\ Loma Linda University Medical Center, Loma Linda California
}

Follow this and additional works at: https://jdc.jefferson.edu/jeffjpsychiatry

Part of the Psychiatry Commons

Let us know how access to this document benefits you

\section{Recommended Citation}

Cheng, MD, Keith (1986) "Dynamic Considerations in Psychiatric Crisis Intervention," Jefferson Journal of Psychiatry. Vol. 4 : Iss. 2 , Article 6.

DOI: https://doi.org/10.29046/JJP.004.2.003

Available at: https://jdc.jefferson.edu/jeffjpsychiatry/vol4/iss2/6

This Article is brought to you for free and open access by the Jefferson Digital Commons. The Jefferson Digital Commons is a service of Thomas Jefferson University's Center for Teaching and Learning (CTL). The Commons is a showcase for Jefferson books and journals, peer-reviewed scholarly publications, unique historical collections from the University archives, and teaching tools. The Jefferson Digital Commons allows researchers and interested readers anywhere in the world to learn about and keep up to date with Jefferson scholarship. This article has been accepted for inclusion in Jefferson Journal of Psychiatry by an authorized administrator of the Jefferson Digital Commons. For more information, please contact: JeffersonDigitalCommons@jefferson.edu. 


\title{
Dynamic Considerations in Psychiatric Crisis Intervention
}

\author{
Keith Cheng, M.D.
}

\section{INTRODUCTION}

One of the most challenging tasks for psychiatrists and psychiatric residents is emergency room triage. This task becomes more frequent as more patients depend on the emergency room for psychiatric treatment. Various social and economic pressures account for an increased utilization of psychiatric triage. The government funds that were to provide community care for the ex-patients of state hospitals have never materialized in adequate amounts (1). Many of these patients become dependent transients who in a crisis must use the emergency room as a psychiatric clinic. To keep premiums down, some insurance companies have eliminated their outpatient psychiatric coverage, often limiting their clients to inpatient treatment only. As a result under-insured individuals appear in the emergency room seeking hospitalization instead of more appropriate outpatient care.

Competent psychiatric triage entails more than simply deciding whether or not to hospitalize. Presumably every patient who comes to the emergency room to be seen in psychiatric triage is in a crisis of sorts. If not admitted, the patient still needs initial crisis intervention, and the triage physician should be capable of intervening effectively. What happens during the first encounter is critical to ensure patient compliance with any recommendation. The decision to admit is often easier than determining the proper outpatient disposition. Rating scales have been devised to screen patients who need hospitalization from those who do not (2), however, currently no scale exists for determining specific outpatient dispositions. In psychiatric triage a quick therapeutic alliance must be formed, an accurate and rapid assessment made, and finally an appropriate disposition devised and put into effect. This process is usually completed in less than an hour. In some busy emergency rooms it must occur even faster, within five to fifteen minutes (3).

The major challenge, then, is to provide an effective intervention in a single time-limited session. For the patient this may be his first and only psychiatric contact. So there is an added pressure on the physician that the initial formulation and disposition be accurate and appropriate. Correct initial interventions

Dr. Cheng is the chief resident at Loma Linda University Medical Center, Loma Linda, California. 
can minimize the untoward effects of discontinuity in initial care and subsequent follow-up. The physician also aims to prevent unnecessary hospitalization and ultimately to guide the crisis patient to an appropriate disposition.

In contrast to more conventional psychotherapies, crisis intervention is more concerned with the current events that have led to a patient's inability to cope. The focus is not on childhood and adolescent memories, but on the causes of the crisis at hand and the matrix of immediate life circumstances from which the crisis emerged. Crisis interventions aim to restore a patient's ability to cope. Crisis therapy is not and should not be concerned with cures or lasting character change. While these outcomes are desirable in some other circumstances, they are not within the scope of this therapeutic modality.

Crisis intervention in psychiatric triage applies the fundamental ideas of the traditional crisis intervention paradigm. But because the intervention must be completed in a single session, certain issues become more critical. The intervenor in this situation must develop a rapport with the patient as soon as possible. Countertransference problems must be identified and corrected on the spot. The physician must also be aware of local referral sources in order to make an appropriate disposition.

\section{HISTORICAL ANTECEDENTS}

Sigmund Freud used brief treatment interventions with contemporaries like Gustav Mahler (4). Erik Erikson made a contribution to crisis theory with his conceptualization of developmental crisis (5). While both Freud and Erikson made contributions to crisis theory, the individual who gave the field its own identity was Erich Lindemann, dubbed the father of crisis intervention for his classic article entitled "Symptomatology and Management of Acute Grief" (6). In this article Lindemann presented his analysis of the 101 patients who lost relatives through medical illness, through death in the armed forces, or death in the disastrous Cocoanut Grove nightclub fire of 1943. Though Lindemann never used the terms "crisis" or "crisis intervention" in his analysis, he clearly outlined the essential concepts of crisis reactions and crisis management. Gerald Caplan, another pioneer of crisis theory, went on to refine the description of crisis reactions, and apply the concept of homeostasis to the developing theory.

As crisis theory evolved, intervention programs such as the "Wellesley Human Relations Service" in Wellesley, Massachusetts, the "Benjamin Rush Center for Problems of Living" in Los Angeles, California (7), and nationwide suicide prevention centers came into being. At the present time, the development of crisis intervention theory has found applications in family therapy, student counseling, and group therapy.

\section{THEORETICAL CONSIDERATIONS}

The dictionary defines the word "crisis" as "a turning point; a decisive moment for better or worse; an emotionally significant event or radical change of status in a person's life." Caplan (8) defines a crisis as an upset in which the 
usual problem-solving process takes longer than normal to return the system to an equilibrium or steady state. This conception assumes that an individual strives to maintain a state of equilibrium by constant adaptation to the pressures of living. Caplan (8) describes four phases in the development of a crisis state. Phase one begins with an initial rise in tension when a hazardous stimulus elicits the usual problem-solving responses. Tension continues and increases in the second phase because habitual coping mechanisms are ineffective. In phase three the individual reevaluates both the problem and the coping methods, and then either tries new ways of problem solving or adopts an attitude of resignation. The fourth phase occurs when neither the new methods of coping nor mere resignation prove to be effective. At this point major disorganization ensues, sometimes with drastic results. During the latter phases, depression, anxiety, and feelings of hopelessness are prominent. From a psychodynamic perspective, the ego regresses to more primitive defense mechanisms. A patient who arrives at the emergency room in crisis is usually in stage three or four.

Most authors agree that the acute stage of crisis lasts no longer than two to six weeks after onset of the crisis stimulus. After that time the crisis resolves. There is a wide range of possible outcomes in relation to the adaptiveness of resolution. Poor outcomes are associated with the development of psychiatric illness. Factors affecting crisis outcome include social norms, the influence of family and friends, or significant others, and the interventions of physicians and mental health workers. "A little help, rationally directed and purposely focused at a strategic time is more effective than more extensive help given at a period of less emotional accessibility" (9). The earlier the situation is treated, the less likely that it will result in a chronic and debilitating maladaptive pattern. This example of primary prevention of psychiatric illness is an important goal of crisis intervention.

Crisis theory stresses the analysis of the immediate and recent internal psychological as well as external environmental factors which contribute to the crisis state. This is in contrast to traditional psychoanalytic theory, which places a premium on lifelong patterns and early childhood occurrences.

The concept of crisis tends to carry a negative connotation; stress is a burden or load under which a person cracks. In crisis intervention, on the other hand, a state of crisis is conceived as a situation that holds growth-promoting potential. A crisis is a transitional period that offers the patient opportunity for personal growth in the face of potential decompensation into mental illness. This is the challenge of crisis intervention. The intervenor aims at helping the patient not only to resolve his problem and restore ego mastery, but to learn and grow from the crisis.

\section{PROCESS AND TECHNIQUE}

Psychiatric crisis intervention is composed of several processes including: formation of a working rapport, abreaction and the gathering of data, dynamic formulation, and disposition. 
In the initial stage, the indispensability of a working rapport is often forgotten. In their haste to decide about hospital admission, triagers often concentrate immediately on getting the facts at the expense of getting to know the patient. If careful attention is not paid to the establishment of rapport, the triager may lose the opportunity to gather valuable information because of a poor working relationship. A little time spent in dealing with the patient's first impressions and feelings about seeing a psychiatrist can facilitate the whole process. In describing the psychiatric interview, Sullivan (10) makes important comments which apply to the initial process of forming rapport. Attention should first focus on the face to face encounter. Address the patient by name. The depersonalization of the emergency room experience is alienating enough without having the psychiatrist forgetting the patient's name. Decide if a handshake is appropriate before blithely violating a patient's personal space. Get the patient to express feelings about seeing a psychiatrist. The response can guide your interventions throughout the session. Share collateral information with the patient. Nothing irritates a patient more than a psychiatrist who does not seem to know the story even after it has already been told. Telling the patient what you have learned from the chart or ancillary personnel gives him a chance to correct erroneous data which are often passed from one source to another. Note your effect on the patient and monitor your initial reactions to the patient's demeanor, in order to know what role the patient needs you to take and when. For instance if a patient appears on the verge of tears and needs to cry, let it happen. This is not the time to start asking questions for a detailed history. While the psychiatrist is busy trying to build rapport, the patient is dealing with many mixed feelings. Do I need to be here? Can I trust this person? Can he understand me? Does he really care? Get the patient to disclose any reservations about coming to the emergency room for help. Your response to this information will help decrease the patient's anxiety and ambivalence.

Learning about the crisis forms the next or middle stage of crisis intervention. During the interchange, the intervenor is gathering important data about the patient's character and life situation which will increase the likelihood of an accurate assessment being made. Meanwhile the patient gets to abreact. Facilitating emotional release or catharsis is in itself often therapeutic.

More often than not, therapists are not active enough in this stage of crisis intervention. Time limitations make purposeful activity essential. Wolberg states "passivity of the intervenor is anathema to short-term therapy" (11). In order to identify the precipitating circumstances and all other significant stressors, the triage physician must feel free to reframe the direction of the interview at appropriate points. Otherwise, important information may never be elicited. Patients often feel even more lost and confused if allowed to talk on at random. During this stage of the intervention, it is important to focus on the central problem or theme. Concentrate on the current life situation rather than on childhood history or information unrelated to the crisis itself. A simplified and rapid method for obtaining the relevant data has been described by Sheldon 
Kardener (12). His system categorizes life experiences into four worlds: The Work-School World; The Familial World, which is subdivided into parentsibling relationships on the one hand, and spouse-children relationships on the other; The Social World, subdivided into friends and social relationships of the same and opposite sex; and The Intrapsychic World, best evaluated by appropriate inquiries about sleep patterns and dream content, in addition to the usual mental status questions when indicated. Reviewing what has happened in these "worlds" during the last two to six weeks of the patient's life should reveal the precipitants of the crisis.

In history taking, the use of empathic interpretations "with the current," as described by Alexander and French (13) helps facilitate catharsis, decreases resistance to revealing significant detail, and at the same time gives the patient emotional support. For example, an agitated veteran with post-traumatic stress disorder, who came to the emergency room angrily complaining about all the abuse he had suffered in Vietnam, was able to express his anger towards his family when the psychiatrist commented on how the veteran had missed appreciation from both the government and his family. As it turned out, the real crisis was that the veteran had been asked by his parents to move out of their house.

If a thorough survey fails to pinpoint any precipitating event, there may be a reason to suspect a psychotic process. In the psychotic patient, trivial stressors may evoke responses that appear grossly or mystifyingly exaggerated.

Once the patient and intervenor have explored the crisis situation, the intervenor needs to reach his diagnostic impressions and dynamic formulation, and at the same time help the patient better understand his predicament. After the patient has given his "story," it is time for the intervenor to check his information and initial impressions by summarizing and clarifying them with the patient. Some patients may introduce a pseudo-complaint or pseudo-crisis as an unconscious way to avoid the real crisis. If this occurs, it is necessary to elicit the actual conflicts by using clarification techniques. The intervenor does this by reflecting back to the patient a clearer, less distorted picture of the confusing array of thoughts, feelings, and events that a patient has been experiencing. This gives patients a chance to gain a less misleading, and therefore more useful, picture of their crisis.

A recapitulation or summary of what the intervenor has come to understand allows the patient to correct any misimpressions that have formed. It also allows the intervenor indirectly to note and question any false assumptions the patient may have. "By the therapist providing a cognitive summary, the patient is encouraged to embrace the concept that a problem can be solved with a tangible solution" (14).

Interpretations put in the form of a question can help assess the patient's psychological mindedness. "What part do you think you played in this crisis?" The response to this question will aid the intervenor later with disposition. Patients, for example, who cannot accept their own role in generating their 
crisis would probably do better in a self-help group than in individual insightoriented therapy.

Aaron Beck's (15) cognitive therapy involves techniques to correct faulty assumptions. Such methods can be effective tools to reduce a sense of confusion and decrease the patient's attachment to ideas that promote maladaptive behavior. Patients in crisis frequently feel that the situation needs to be corrected immediately, even when such expectations are impossible. If a patient can relinquish faulty or unrealistic assumptions in this situation, a significant amount of pressure can be lifted from the already urgent predicament. Experiencing less self-imposed pressure, the patient will feel more able to deal with the crisis.

In the final stage of crisis intervention, intervenor and patient collaborate on disposition. Disposition is the process of making and implementing a treatment plan. Because of their crisis state, patients in the emergency room are usually regressed, and dependent on the intervenor for support and advice. They also usually experience a natural positive transference towards an intervenor whom they are finding helpful. The combination of regression and positive transference makes the patient more readily amenable to therapeutic suggestion. "Suggestion is the attempt to induce beliefs in the patient, to have him adopt ideas or attitudes which are different and more healthy than his present ones" (16). When it comes to making decisions, crisis patients are more apt to be illogical than logical. Here again the intervenor must actively guide the patient toward a rational use of both internal and external resources. One of the best ways of applying this principle is to have patients list all the possible options they can think of to handle their crisis. The intervenor can help them assess the advantages and disadvantages of the various alternatives, or suggest additional options not on the list.

For patients who are not psychologically minded, or introspective, or who are too regressed to make rational decisions, techniques of persuasion must be used. Such techniques serve to get the patient to try out different and less self-destructive behavior. Take for example, an alcoholic who insists that the only way he can rid himself of his dependency problem is to get a prescription for Librium ${ }^{\circledR}$. The physician needs to emphasize with an attitude of firmness and concern that prescribing Librium ${ }^{\circledR}$ is only substituting one addictive substance with another, and will never end his dependency behavior. Instead his best options are to get into either an outpatient or inpatient alcohol treatment program.

As the intervenor works with the patient, listing alternatives and exploring all possible options, the patient regains some ego mastery. It is important not to settle on a single alternative. A hierarchical list should be drawn up, so that if the first plan does not succeed, a reasonable backup plan is available. If at all possible, the crisis patient should reach a decision about treatment with the intervenor before leaving the emergency room. The patient is more likely to comply with follow-up if direct contact can be made with the chosen referral 
resource by telephone or in person that same day. Whenever possible, family members should be included in this process. Studies have shown that follow-up compliance is greatly enhanced when significant others are involved in the disposition and follow-up process (17). If a patient cannot reach the referral resource in the presence of the intervenor, a verbal or even written contract should be made between the two. Everything possible should be done to ensure compliance with disposition plans.

Psychiatrists and residents do not always know their referral sources as well as they should. Perhaps they consider making referrals a job for the social workers or clinic intake secretaries. This may be acceptable if a 24-hour social worker is on duty, but many hospitals are without this luxury. Continuity of care should be maintained as much as possible. If psychiatric professionals have the time to make dispositions, they should certainly complete their interventions rather than leave it up to someone else. It should surprise no one when a patient fails to make it to an outpatient clinic for follow-up, if all he is told in the emergency room is, "Well, you don't need admission, so why don't you go to the clinic."

A final note about disposition. Sometimes it is the family, not the identified patient, that needs referral. A family that chronically brought a schizophrenic member to the emergency room stopped making these trips once a thoughtful resident referred them to the "Alliance for the Mentally Ill." It was learned later that the schizophrenic's relatives felt constantly distressed and alone in their struggle to cope with their mentally disturbed family member. Once they found support with others who shared their frustrations, they no longer had to seek it in the hospital emergency room.

It is essential to realize that actually two processes take place concurrently during each stage of a crisis session, one in the patient, and one in the therapist. The intervenor must work to stay with the patient. It is difficult to press for information, the task of the middle stage of crisis intervention, if the patient is still in the first stage trying to form a working rapport with the therapist.

\section{PITFALLS TO AVOID}

In all psychotherapy, countertransference can block the therapeutic process. In triage crisis work, too, unnoticed countertransference issues can slow up or totally block the intervention process. In contrast to other therapeutic situations, it is critical to correct countertransference problems on the spot when restriction to a single session precludes any later correction.

The way to avoid countertransference pitfalls in the emergency room is to be aware of the possibilities in advance. Probably the most common mistake in this situation is to take too much responsibility for the patient. The characteristic helplessness and passivity of the crisis patient tempt the inexperienced intervenor to become a rescuer. "The painful unconscious identification with the frightened child-like patient fosters an urgent and illusory identification 
with the wished for powerful parent who assumes complete control of and responsibility for the patient - a grandiose rescue fantasy" (18). One should not do for patients what patients can do for themselves. An intervenor should beware of identifying too readily with patients with whom similar life problems are shared. A blindspot about the real issues can lead therapists into vicariously working on their own conflicts through their patients. Intervenors may also fall into judgmental and rejecting attitudes. Observing the affective response that crisis patients generate in those around them, can help keep an intervenor from overreacting. An extremely frustrated patient has a way of frustrating those who try to help him. Intervenors can recognize the emotions that the patients arouse in them and use it as a barometer of the patient's feelings and frustrations.

Burn-out is common in all emergency room physicians. When working in triage it is important to have an awareness of becoming fatigued. A tired intervenor will be more apt to settle for formulations based on incomplete data. He will also tend to lump patients into the same categories instead of individualizing his dispositions. Above all, the intervenor must realize that one cannot solve everything in the triage setting. As physicians we often expect too much of ourselves in trying to help our patients.

\section{DISCUSSION}

The application of crisis intervention techniques to psychiatric triage couples two parts of psychiatry that naturally fit together. The triage physician makes daily decisions about whether a patient should be admitted to the hospital or referred to outpatient treatment. If the patient is not to be admitted, crisis intervention continues at once in the emergency room. Intervention techniques provide a tool not only to enhance patient compliance with outpatient disposition, but also to help prevent unnecessary hospitalization in the future. One of the goals of crisis intervention programs is to prevent the development of mental illness, a prime example of primary prevention in psychiatry. Even the emergency room lets us practice primary psychiatric prevention if we use proper crisis intervention techniques in psychiatric triage.

A review of the psychiatric literature on crisis intervention since the original contributions of Lindemann and Caplan in the forties, fifties, and sixties shows few new contributions to the field. "It appears that crisis theory has not changed dramatically from those early pioneering days. This has occurred because most theorists have not operationalized crisis theory into clear, conceptual treatment plans. Until this is done it will be difficult to evaluate the effectiveness of crisis intervention" (19). The development of brief psychotherapies makes a good model for the further evolution of crisis intervention techniques. The elaboration and refinement of crisis intervention to a state where outcome studies can measure effectiveness is the next needed development. Such research and study should continue to improve and evaluate psychiatric crisis intervention as a 
means of increasing outpatient treatment compliance and decreasing the need for hospitalization.

\section{REFERENCES}

1. Mollica RF: From Asylum to Community. N Engl J Med 308:367-373, 1983

2. Bengelsdorf H, Levy LE, et al: A Crisis Triage Rating Scale. J Nero Ment Dis 172:424-430, 1984

3. Baxter S, Chodoroff B, Underhill R: Psychiatric emergencies: Dispositional determinants and the validity of the decision to admit. Am J Psychiatry 124:1542-1548, 1968

4. Trilling L, Marcus E (eds): The Life and Work of Sigmund Freud. New York, Basic Books, 1961

5. Erikson EH: Identity and the Life Cycle. Psychological Issues Selected Papers 1:50-100, 1959

6. Lindemann E: Symptomatology and Management of Acute Grief. Am J Psychiatry 101:141-148, 1944

7. Jacobson GF: Programs and Techniques of Crisis Intervention, in American Handbook of Psychiatry. Edited by Arieti S. Volume 4, Chapter 55, pp. 810-825, 1975

8. Caplan G: Principle of Preventive Psychiatry. New York, Basic Books, 1964

9. Rapoport L: The State of Crisis: Some Theoretical Considerations. Social Service Review 36:211-217, 1962

10. Sullivan HS: The Psychiatric Interview. New York, W.W. Norton \& Company, 1954

11. Wolberg LR: Short-term Psychotherapy. New York, Grune and Stratton, 1965

12. Kardener SH: A Methodologic Approach to Crisis Therapy. Am J Psychother 29:4-12, 1975

13. Alexander F, French TM: Psychoanalytic Therapy Principles and Application. Lincoln, Bison Books, 1980

14. Sifneos PE: Short Term Dynamic Psychotherapy. New York, Plenum Publishing Corporation, 1979

15. Beck AT, Rush AJ, Shaw BF: Cognitive Therapy of Depression. New York, The Guilford Press, 1979

16. Bibring E: Psychoanalysis and the Dynamic Psychotherapies. J Am Psychoanalytic Association 2:745-68, 1954

17. Sweeney JA, Von Bulow B, Shear MK: Compliance and Outcome of Patients Accompanied by Relatives to Evaluations. Hosp Community Psychiatry 35:1037-1038, 1984

18. Glick RA, Meyerson AT: The Use of Psychoanalytic Concepts in Crisis Intervention. Int J Psychoanalytic Psychotherapy 8:171-188, 1980

19. Smith LL: A Review of Crisis Intervention Theory. Social Casework 59:397-405, 1978 